\title{
ICR-Like and Osteoarthritis in Geriatric Patients: Pilot Study at an RCH Facility
}

\author{
Alessandro Greco ${ }^{1 *}$, Valentina Lorengo ${ }^{2}$, Nadia Malfatti ${ }^{2}$, Elisabetta Zanella ${ }^{2}$, Laura \\ Sarnella', Manuela Sicher ${ }^{2}$, Ilaria Frati' ${ }^{2}$ and Nicolò Panza ${ }^{2}$
}

${ }^{1}$ PAPS (Public Agency for Personal Services) RCH Cles, Italy

${ }^{2}$ Department of Physiotherapy, Physiotherapy Service PAPS (Public Agency for Personal Services) RCH Cles, Italy

\begin{abstract}
Introduction: Osteoarthritis $(\mathrm{OA})$ is a rheumatic disease that affects the joints. It is a chronic degenerative disorder of an inflammatory nature affecting joint elements (cartilage, synovia, capsule). OA is one of the most common causes of painful disorders, affecting about $10 \%$ of the general adult population and $50 \%$ of people over the age of 60 years.

One of the most widely used conservative approaches for treating pain from OA is the use of physical therapies. Among these, the use of low frequency low intensity electromagnetic fields (ELF-EMF) has attracted a rapid growth in interest and studies in recent years, thanks to its ease of use and the very safe nature of the treatment.

One of the most complete and widely accredited explanations for the interaction between ELF-EMF and biological systems is the Ion Cyclotron Resonance-like (ICR-like) phenomenon.

For this reason, at the Public Agency for Personal Services (PAPS) Residential Care Home (RCH) "Santa Maria" in Cles (TN, Italy), it was decided to conduct a pilot study to verify the effects of ICR-like therapy on patients affected by OA.

Materials and methods: This observational pilot study made use of a SEQEX device to treat $10 \mathrm{RCH}$ residents with OA in different an atomical areas. Treatment with ELF-EMF was administered in packets of frequencies between $40 \mathrm{and} 80 \mathrm{~Hz}$, at a field intensity of $20 \mu \mathrm{T}, 3$ times per week for a total period of 4 months of therapy, followed by 4 months of follow-up.

The effects were analyzed on: pain (at rest "NRS_R" and in movement "NRS_M") with assessment on the NRS scale, quality of life QoL with assessment on the SF-12 and EQ-5D scales, joint mobility, and the need for analgesic drugs in order to control pain.

Results: The results achieved for the control of pain (NRS_R and NRS_M) were very satisfactory with a significant reduction in pain $\left(\mathrm{p}_{\mathrm{NRS}_{-} \mathrm{R}}=0.024, \mathrm{p}_{\mathrm{NRS} \_\mathrm{M}}=0.048\right)$, which also persisted in follow-up $\left(\mathrm{p}_{\mathrm{NRS} \_\mathrm{R}}=0.015, \mathrm{p}_{\mathrm{NRS} \_\mathrm{M}}=0.011\right)$.

The QoL exhibited a clear improvement during the treatment period $(\mathrm{p}=0.041)$, declining during the follow-up for diverse reasons. Similarly, during the treatment cycle there was an improvement in joint mobility (in the joint treated for OA) of $75 \%$.

The need to assume analgesic drugs was completely eliminated during the treatment cycle $(\mathrm{p}=0.018)$ and persisted in follow-up.

Conclusions: Considering the very satisfying results, ease of use, and high level of safety, ICR-like treatment may represent a valid option for the treatment of OA pain. The figures achieved deserve to be confirmed in a larger and more highly structured study.
\end{abstract}

\section{Introduction}

Osteoarthritis $(\mathrm{OA})$ is a rheumatic disease that affects the joints [1]. It is one of the most common causes of painful disorders [1], affecting about $10 \%$ of the general adult population and $50 \%$ of people over the age of 60 years $[2,3]$.
*Corresponding author: Alessandro Greco, Medical Director, PAPS (Public Agency for Personal Services) RCH Cles, Italy

Accepted: November 01, 2018;

Published online: November 03, 2018

Citation: Greco A, Lorengo V, Malfatti N, et al. (2018) ICRLike and Osteoarthritis in Geriatric Patients: Pilot Study at an RCH Facility. J Orthop Rheumatism 2(1):33-46

Copyright: (c) 2018 Greco A, et al. This is an open-access article distributed under the terms of the Creative Commons Attribution License, which permits unrestricted use, distribution, and reproduction in any medium, provided the original author and source are credited. 
The main characteristic of osteoarthritis is the loss of hyaline cartilage associated with a subchondral reaction [4]. This leads to fibrillation of the cartilage, with chondrocyte proliferation and formation of cellular agglomerations, increased blood flow in the subchondral bone with a secondary increase in bone pressure and relative sclerosis, promoting cystic and marginal osteophytic formations [5]. The synovial membrane appears hyperemic and hypertrophic, the capsule is edematous and fibrosclerotic [5].

Defining the disease arthrotic indicates a chronic degenerative disorder, inflammatory in nature and affecting the bone structures and joint elements (cartilage, synovia, capsule) $[4,6]$.

The phlogistic process is thus one of the main factors in arthrotic disease [6,7]. Acute relapsing of the inflammation process in the joints is reflected in accentuation of the typical clinical characteristics of the disease: pain, joint swelling, and reduced joint functionality. Currently there is no truly effective therapy for arthrotic disease and treatment is limited to the symptoms [8] of pain, swelling, and stiffness using pharmaceuticals $[8,9]$, orthopedics [10], or surgery $[11,12]$. Physiotherapy is indicated for both preventive and therapeutic amelioration of joint flexibility and mobility $[13,14]$. Other useful measures are an adequate exercise regime [15] and limiting weight [16].

Without going into the various types of approach to the problem, it is right to focus attention on the pharmacological approach, which is a vast reality in clinical orthopedic practice and in "self-medication", very often representing a watershed between a more interventionist approach (surgery) and a more conservative approach (physiotherapeutic- orthopedic).

Pharmaceuticals for treating osteoarthritis can be assumed orally in the form of tables or syrups, applied directly as creams or lotions [17], or directly injected into affected joints. The following list includes the primary categories.

- NSAIDs (nonsteroidal anti-inflammatory drugs) are the most widely used to counter inflammation and associated pain [18]. They are obtained over-thecounter or under prescription and include aspirin, celecoxib, ibuprofen, and naproxen, etc.

- Analgesic pain killers available over-the-counter or under prescription [19] and include acetaminophen [20], opioids [8], and tramadol [8] (an atypical opioid).

- Hyaluronic acid is a natural component of joint fluid, serving as a lubricant and shock absorber. It appears to diminish in joints affected by osteoarthritis and can be injected in a surgical procedure [21].
- Corticosteroids provide a very marked anti-inflammatory action and can be taken orally or directly injected into an affected joint in a surgical procedure [22].

The objective of pharmacological treatment is to reduce symptoms, combined with a conservative approach designed to reduce and delay the evolution of the disease $[1,8,19]$.

In this respect it is very important to try and improve patient response to conservative treatment in order to improve the quality of life and delay the resort to surgery.

As an integration or alternative to the traditional pharmacological approach, many OA sufferers adopt natural or alternative therapies [23] to address symptoms and improve their overall wellbeing. Some popular examples are massage, acupuncture/acupressure, various relaxation techniques, hydrotherapy, and dietary supplements [23-25].

In the sphere of integrated medicine, physical therapies [26-28] have been found to be of great value administered within an institutional or home physiotherapeutic program.

Among these the use of Extremely Low Frequency, Extremely Low Intensity Electromagnetic Fields (ELFEMF) is a valid therapeutic option for individuals suffering from OA [28-42].

The Ion Cyclotron Resonance-like phenomenon (ICR-like) is a physical model regarding ionic flows through cellular membranes induced by the application of ELF-EMF [43-51]. It was proposed in 1984 by the American physicist Abraham Liboff [43] as a hypothesis to explain the results obtained by the physicists Adey and Blackman in their studies [49] regarding these flows. Liboff hypothesized that the ELF-EMF administered in the experiments interacted with the geomagnetic field (GMF) [44,51] and facilitated transit of ionic species through the cellular membranes [45], thus acting as a modulator of the amount of movement of the ions.

The therapeutic approach based on the use of ELFEMF has been investigated in diverse medical fields, including in particular physiology [43-64] and osteoarticular physiopathology [29-32,55,65-73]. It should also be noted that the first device based on ICR-like for medical use (FDA-approved in 1986) was an instrument for enhancing the repair of bone fractures. As regards use in arthrotic disease, the literature includes some interesting articles, which reveal the biological effectiveness of ELF-EMF on chondrocytes [35], sampled from arthrotic joints in vitro, with an effect of anti-inflammatory modulation $[42,52]$. The literature also includes a clinical study involving the administration of ICR-like on 143 patients 
Citation: Greco A, Lorengo V, Malfatti N, et al. (2018) ICR-Like and Osteoarthritis in Geriatric Patients: Pilot Study at an RCH Facility. J Orthop Rheumatism 2(1):33-46

[29] with musculoskeletal dysfunction of diverse pathogenesis (rheumatic, arthrotic, osteoporotic, traumatic, post-surgical) which produced good results in pain control and postural aspect.

While there is still much to be understood on how ELF-EMF interact with living structures, the literature includes different physical models that attempt to describe the mechanisms of action. At the current state of art, ICR-like represents for the authors one of the better explanation for the phenomenon and deserving furthermore detailed research into its applications in the medical sphere.

There are diverse hypothesized effects of ICR-like on biological systems and among those useful for therapeutic applications, beyond the osteoarticular sphere, of particular note (and fundamental for the present project) is ICR-like as a positive regulator of the oxidation balance [74-78]. Among the various studies in the literature on this theme, deserving of mention are a number conducted in Italy: 2 fundamental testimonies bearing the signatures of Prof. Ruggero Rossi of the University of Perugia (in 2002) and Dr. Edoardo Rossi of the San Martino Hospital of Genoa (in 2003 and in review in 2008). It should be noted that both these studies made use of a SEQEX brand medical device, which, as amply explained in the materials and methods chapter, was also chosen as the ICR-like instrument for the present project.

In the light of all the above observations, the starting point for the present study was to hypothesize that the ICR-like phenomenon, acting as a modulator of the inflammatory process, could represent an ideal non-pharmacological approach to OA.

\section{Materials and Methods}

This pilot study, observational in nature, was conducted within the Public Agency for Personal Services (PAPS) Residential Care Home (RCH) "Santa Maria", located in Cles (TN, Italy), home to 147 elderly pluripathological individuals, many of whom with variable degrees of cognitive deterioration calculated using the Mini-Mental (MMSE) test.

Furthermore, considering that facilities like this are not intended for research but only to provide assistance, in order not to excessively burden the organization it was decided to focus on a limited number of residents under the following selective criteria:

- MMSE not older than 6 months from recruitment with a score greater or equal to 25 ;

- Diagnosis of arthrotic or arthritic disease by a specialist;

- Arthrotic symptoms present and active;
Table 1: Joints treated.

\begin{tabular}{|l|l|}
\hline Subject & Joint with OA \\
\hline A & cervical spine + shoulder \\
\hline B & knee \\
\hline$\Gamma$ & shoulder \\
\hline$\Delta$ & cervical spine \\
\hline E & shoulder \\
\hline Z & cervical spine \\
\hline$H$ & knee \\
\hline$\Theta$ & lumbar spine \\
\hline
\end{tabular}

- Pain assessment scale NRS (Numerical Rating Score) $\geq 5$ before treatment with SEQEX;

- Willingness of the subject to undergo the complete treatment cycle.

On the basis of the inclusion criteria the number of residents involved in this preliminary study was 10 (7 women and 3 men), with a drop out of 2 subjects: one due to reassessment of MMSE falling below the inclusion threshold, the other due to the desire to interrupt the therapeutic protocol after the first treatment. Thus a total of 8 subjects ( 7 women and 1 man) completed the complete study and follow-up cycle foreseen in the initial experimental set-up.

The subjects involved suffered from OA in different anatomical areas, as listed in the following (Table 1).

During this preliminary observational study, a SE$\mathrm{QEX}^{\oplus}$ device was used, produced and distributed by the Italian company S.I.S.T.E.M.I. srl (Trento, Italy) and certified CSQ ISO-13485. This device has the capacity to produce complex electromagnetic fields by an analogical mechanism across a frequency range of 1 to $80 \mathrm{~Hz}$ and at intensities of 1 to $20 \mu \mathrm{T}$. The field parameters are tested by the manufacturing company using specialized instrumentation: the device used for this purpose is a Gaussmeter GM 08 produced by the company Hirst. The administration of the electromagnetic field produced by the control unit of the treatment device (on which the parameters of the electromagnetic field can be set), is achieved through a mat inside of which a Helmholtz coil generates the ELF-EMF. The patient lies down on the mat and receives non-focused total body treatment with the desired electromagnetic fields.

In this preliminary observational study, a complex treatment was applied comprising 9 intensity and frequency pairs (called "steps"), with a time-on for presence and time-off for absence of field. Combinations of the following waveforms were used in the different steps: sinusoidal, sawtooth, square. The characteristics are set out in the table below (Table 2).

Each treatment administered had a duration of 27 minutes and in total each subject underwent therapy 3 
Table 2: Table of electromagnetic fields used for treatment. Each step had a duration of 3 minutes. Time-on and -off are measured in seconds.

\begin{tabular}{|l|l|l|l|l|}
\hline Step & $\begin{array}{l}\text { Intensity } \\
(\boldsymbol{\mu T})\end{array}$ & $\begin{array}{l}\text { Frequency } \\
(\mathbf{H z})\end{array}$ & $\begin{array}{l}\text { Time-on } \\
(\mathbf{s})\end{array}$ & $\begin{array}{l}\text { Time-off } \\
(\mathbf{s})\end{array}$ \\
\hline 1 & 20 & 40 & 9 & 3 \\
\hline 2 & 20 & 57 & 9 & 3 \\
\hline 3 & 20 & 67 & 2 & 1 \\
\hline 4 & 20 & 62 & 2 & 1 \\
\hline 5 & 20 & 66 & 6 & 8 \\
\hline 6 & 20 & 71 & 6 & 5 \\
\hline 7 & 20 & 75 & 6 & 5 \\
\hline 8 & 20 & 77 & 4 & 2 \\
\hline 9 & 20 & 80 & 5 & 2 \\
\hline
\end{tabular}

times per week for 4 months, for a total of 48 treatment sessions for each subject. Treatment was administered using a mat to administer non-focused total body treatment. An addition to treatment with the mat an accessory called a Pro Padwas also used, positioned on the joint being treated. This accessory administers the same electromagnetic treatment as the mat but concentrated on the treatment area.

All the therapy was administered using the same device in the same environment, which was the nursing home gymnasium.

- The parameters assessed for this study were:

- Pain at rest (on the NRS scale);

- Pain on passive mobilization of the area affected by OA (on the NRS scale);

- Assessment of joint mobility;

- Assessment of quality of life (QoL) with the SF-12 and EQ-5D questionnaire;

- Weekly assumption of analgesic therapy on demand.

The primary end points of the study were: reduced pain, both at rest and under mobilization, and improvement of the QoL.

Secondary end points of the study were: assessment of joint mobility, assumption of analgesic therapy on demand calculated on a weekly basis.

As regards joint mobility, because of the different anatomical areas of the joints involved, it was not possible to conduct a univocal assessment, and so it was decided to conduct the estimation using Boolean operators, with the value "true $=1$ " representing an improvement in mobility compared to T0 and the value "false $=0$ " representing no improvement of the same. A cut off for significance was defined as an improvement in mobility equal to or greater than $75 \%$.

The assessment scale was measured at T0, half way through the treatment cycle (T1), at the end of the treat- ment cycle (T2), and at the follow-up 4 months after termination of treatment $(\mathrm{F})$. All the assessments were conducted by physiotherapy staff of the facility and recorded both in the study diary and in the database of parameters in the resident's personal clinical record.

\section{Nrs Pain Assessment Scale}

The scale known as the Numerical Rating Scale (NRS) is based on a scale of 11 degrees from 0 to 10 , when 0 corresponds to a total absence of pain, and 10 represents the worst pain the patient can imagine. Pain assessment is conducted by asking the patient to assign a score to their perceived pain $[53,79]$.

The scale was used both for pain at rest and under mobilization.

\section{Quality of life assessment scale Sf-12 and Eq-5d}

The SF-12 questionnaire and the short version of the Short-Form Healthy Survey 36 (SF-36) questionnaire [80]. Using 12 of the 36 questions of the original questionnaire it is possible to investigate just two summary indexes of the 8 original scales. These are the PCS (Physical Component Summary) for physical state and MCS (Mental Component Summary) for mental state. The strong points of this questionnaire, which is also suitable for self administration, are brevity and ease of use. This questionnaire was used in Italy in the year 2000 (among other occasions) in a multi-purpose ISTAT investigation of the state of health of Italians and a reference database is available with data from a sample of 61,434 subjects representative of the Italian population. The literature provides wide-ranging examples that demonstrate the validity and reliability of the short version.

The Euro QoL or EQ-5D is a standardized instrument that makes it possible to measure the state of health of interviewees and their quality of life, on the basis of which it is possible to evaluate health care provision, a technique, or a technology.

In the present study the EQ-5D questionnaire was not administered directly to the participants, and instead the values were obtained from an algorithm using the results of the SF-12 questionnaire $[81,82]$.

While there are many elements that can influence the QoL of an individual, without doubt pain is one of the most important and influential aspects, especially among the elderly. For this reason, considering the pluripathological state of the subjects involved (and so with a high risk of deterioration in QoL for reasons external to the study), it was decided to monitor how this was modified by the cycle of therapy under examination.

\section{Results}

The results achieved are set out below. Each table and 


\section{NRS at REST}

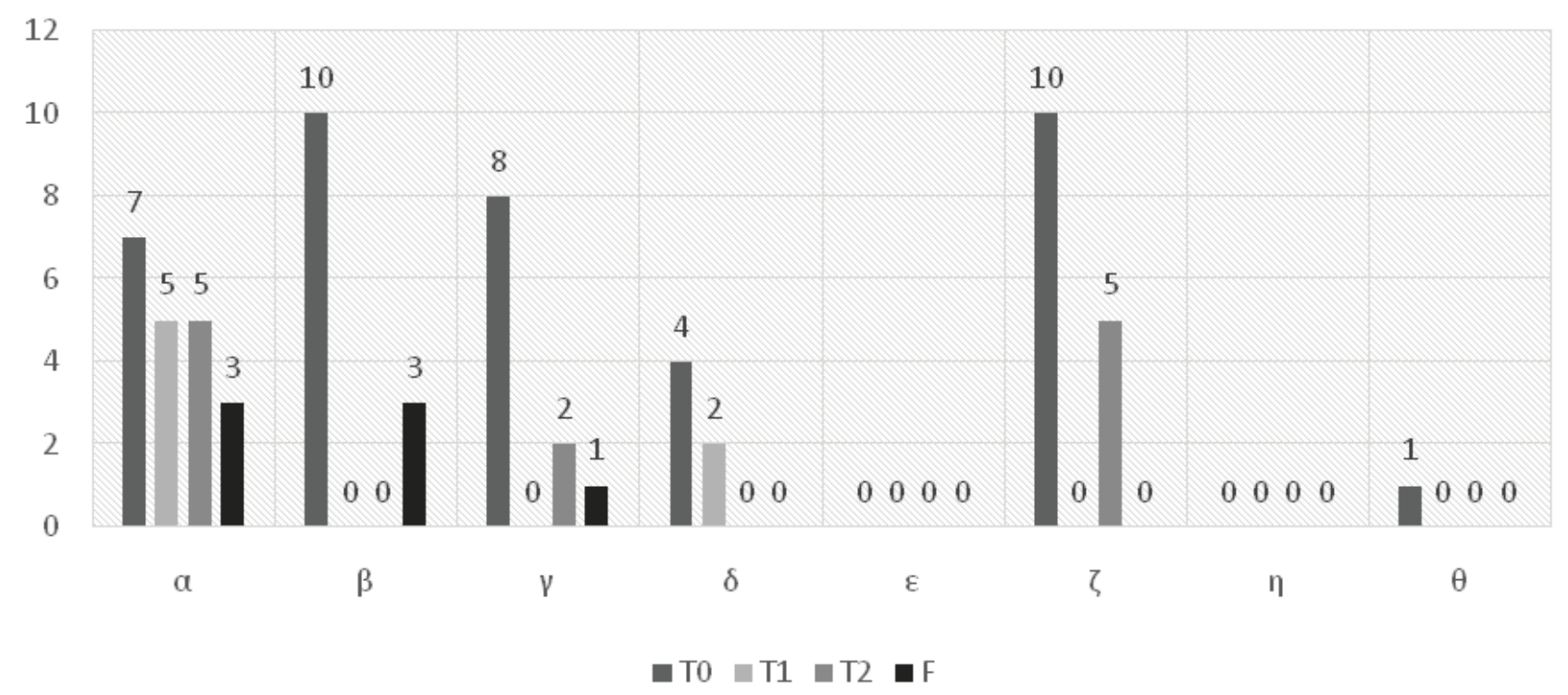

Figure 1: The diagram shows the reduction of pain at rest during the treatment and in follow-up. The reduction is continued also during follow-up period.

Table 3: NRS score at rest of subjects at the different times.

\begin{tabular}{|l|l|l|l|l|}
\hline Subject & T0 & T1 & T2 & F \\
\hline A & 7 & 5 & 5 & 3 \\
\hline B & 10 & 0 & 0 & 3 \\
\hline I & 8 & 0 & 2 & 1 \\
\hline$\Delta$ & 4 & 2 & 0 & 0 \\
\hline E & 0 & 0 & 0 & 0 \\
\hline Z & 10 & 0 & 5 & 0 \\
\hline H & 0 & 0 & 0 & 0 \\
\hline$\Theta$ & 1 & 0 & 0 & 0 \\
\hline
\end{tabular}

relative bar chart represents one of the parameters analyzed in the study (subjects are named with Greek letters in increasing order). For statistical analysis a two-tailed Student's t-distribution was calculated, with a confidence interval of $95 \%$.

\section{NRS at Rest}

The following table sets out the assessment on the NRS pain scale at rest (NRS_R) from T0 to F (Table 3 and Figure 1).

At the start of therapy (T0), the average perceived pain at rest by the subjects involved was 5 on the NRS scale. Already in the middle of the cycle (T1) there was a highly significant reduction, with an average NRS of 0.85 $\left(\mathrm{p}_{\mathrm{T} 0-\mathrm{T} 1}=0.033\right)$. At the end of the therapy cycle (T2) there was a reduction in perceived pain in the subjects with an average of $1.5\left(\mathrm{p}_{\text {T0-Т2 }}=0.024\right)$, with a slight non significant average increase relative to $\mathrm{T} 1$.

In the follow-up (F) the average perceived pain at rest was 0.87 on the NRS scale, indicating a further reduction
Table 4: NRS score under movement of subjects at the different times.

\begin{tabular}{|l|l|l|l|l|}
\hline Subject & T0 & T1 & T2 & F \\
\hline A & 8 & 5 & 6 & 0 \\
\hline B & 7 & 3 & 8 & 7 \\
\hline I & 7 & 6 & 5 & 4 \\
\hline$\Delta$ & 5 & 7 & 5 & 5 \\
\hline E & 7 & 5 & 6 & 5 \\
\hline Z & 10 & 5 & 5 & 0 \\
\hline H & 7 & 4 & 5 & 0 \\
\hline$\Theta$ & 8 & 7 & 7 & 0 \\
\hline
\end{tabular}

in perceived pain not statistically significant relative to $\mathrm{T} 2\left(\mathrm{p}_{\mathrm{T} 2-\mathrm{F}}=0.46\right)$, against a highly significant reduction relative to $\mathrm{T} 0\left(\mathrm{p}_{\text {T0-F}}=0.015\right)$.

\section{NRS under Mobilization}

The following table sets out the assessment on the NRS pain scale under passive mobilization (NRS_M) from T0 to $\mathrm{F}$ (Table 4 and Figure 2).

At the start of therapy (T0), the average perceived pain by the subjects involved during passive mobilization maneuvers, was 7.37 on the NRS scale. Already in the middle of the cycle (T1) there was a highly significant reduction, with an average NRS of $5.25\left(\mathrm{p}_{\mathrm{T} 0 \mathrm{~T} 1}=0.027\right)$. At the end of the therapy cycle (T2) the reduction of perceived pain was confirmed with an average of 5.87 ( $\mathrm{p}_{\text {TO-T2 }}$ $=0.048)$, substantially unvaried relative to T1.

In the follow-up (F) the average perceived pain during passive mobilization maneuvers was 2.63 on the NRS scale, indicating a further reduction in perceived pain of 


\section{NRS under PASSIVE MOBILIZATION}

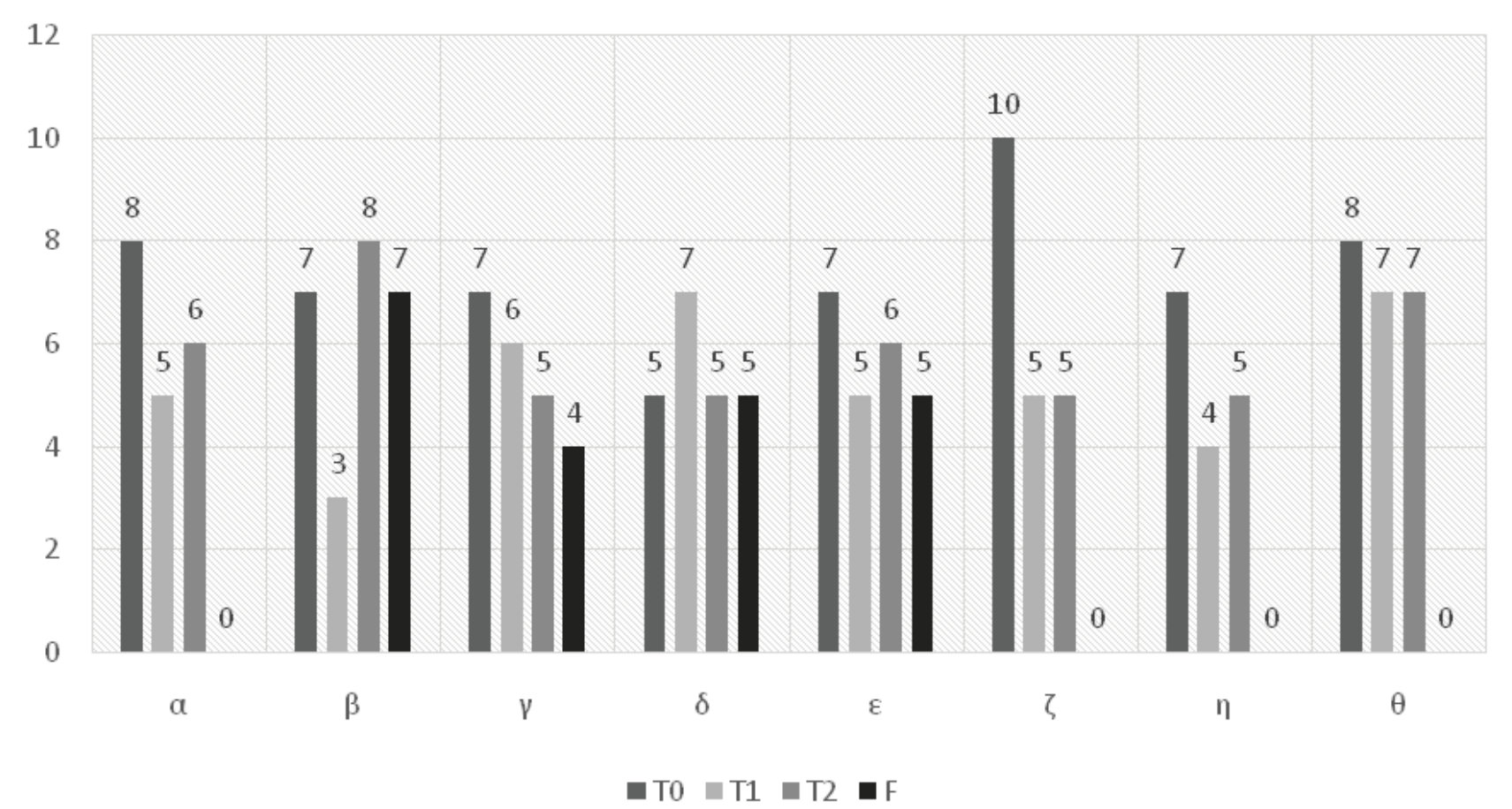

Figure 2: The diagram shows the reduction of pain under passive mobilitazion during the treatment and in follow-up.

Table 5: PCS-12 score of subjects at the different times.

\begin{tabular}{|l|l|l|l|}
\hline Subject & T0 & T2 & F \\
\hline A & 52.59095 & 41.05225 & 31.40312 \\
\hline B & 40.44007 & 36.71192 & 43.52063 \\
\hline I & 39.26568 & 48.27925 & 30.70767 \\
\hline$\Delta$ & 41.48649 & 39.10624 & 39.43508 \\
\hline E & 38.49879 & 27.34437 & 24.32041 \\
\hline$Z$ & 43.12439 & 42.4706 & 44.03994 \\
\hline$H$ & 36.09994 & 44.95783 & 28.46642 \\
\hline$\Theta$ & 42.78881 & 38.55161 & 38.92612 \\
\hline
\end{tabular}

Table 6: MCS-12 score of subjects at the different times.

\begin{tabular}{|l|l|l|l|}
\hline Subject & T0 & T2 & F \\
\hline A & 33.11005 & 48.18005 & 53.95756 \\
\hline B & 40.60363 & 47.19339 & 36.79221 \\
\hline I & 45.11799 & 40.23073 & 51.5229 \\
\hline$\Delta$ & 51.76064 & 50.70666 & 42.19351 \\
\hline E & 46.79973 & 60.42104 & 60.45586 \\
\hline Z & 45.00554 & 52.10619 & 46.72127 \\
\hline H & 41.54199 & 42.00883 & 51.41535 \\
\hline$\Theta$ & 30.08387 & 43.67253 & 53.7314 \\
\hline
\end{tabular}

statistical significance relative to both $\mathrm{T} 2\left(\mathrm{p}_{\mathrm{T} 2-\mathrm{F}}=0.012\right)$, and $\mathrm{T} 0\left(\mathrm{p}_{\mathrm{T} 0-\mathrm{F}}=0.011\right)$.

\section{SF-12 and EQ-5D}

The following table sets out the assessment of the questionnaire on the quality of life SF-12 (SF12) of the subjects treated from T0 to F, calculated separately for the two indicators PCS and MCS. The questionnaire was completed only at T0, T2, and F. The SF-12 questionnaires were completed by each subject autonomously (Table 5 and Figure 3).

At the start of therapy (T0), the average PCS-12 value was 41.78 . At the end of the treatment cycle the average score was 39.81 demonstrating that the perception of physical limitation (in self care and daily activity) increased over all.

At the follow-up (F), the increase in perception of physical limitation was confirmed (average 35.10).

This figure in itself does not indicate an overall deterioration in the quality of life, but rather a deterioration in physical capacities, which can be negatively influenced by events external to the treatment under examination and in which pain is one of the pre-eminent causes but not the only one (Table 6 and Figure 4).

At the start of therapy (T0), the average MCS-12 value was 41.75. At the end of the treatment cycle the average score was 48.06 demonstrating an increase in psychological wellbeing perceived by the subjects involved of statistical significance $\left(\mathrm{p}_{\mathrm{T} 0 \text { - } 2}=0.049\right)$.

At the follow-up (F), there was a further slight increase in psychological wellbeing (average 49.60) relative to $\mathrm{T} 2$, representing a consolidated statistically significant improvement in psychological wellbeing $\left(\mathrm{p}_{\mathrm{T} 0-\mathrm{F}}=0.049\right)$ (Table 7 and Figure 5). 


\section{QUESTIONNAIRE SF-12: PCS}

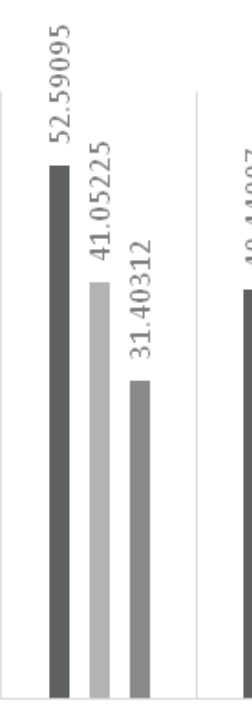

A

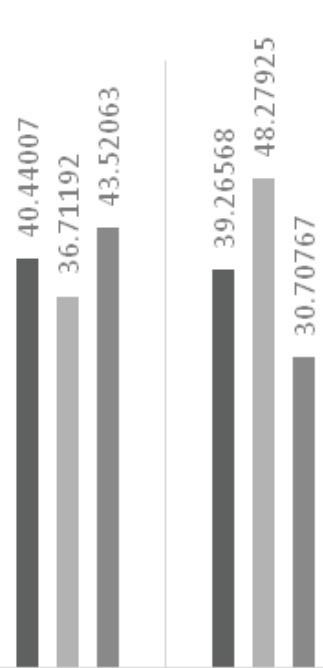

B

$\square \mathrm{T} 0 \quad \mathrm{~T} 2 \square \mathrm{F}$

Figure 3: The diagram shows the variation of PCS-12 score during the treatment and in follow-up. PCS-12 investigates the physical aspects of quality of life.

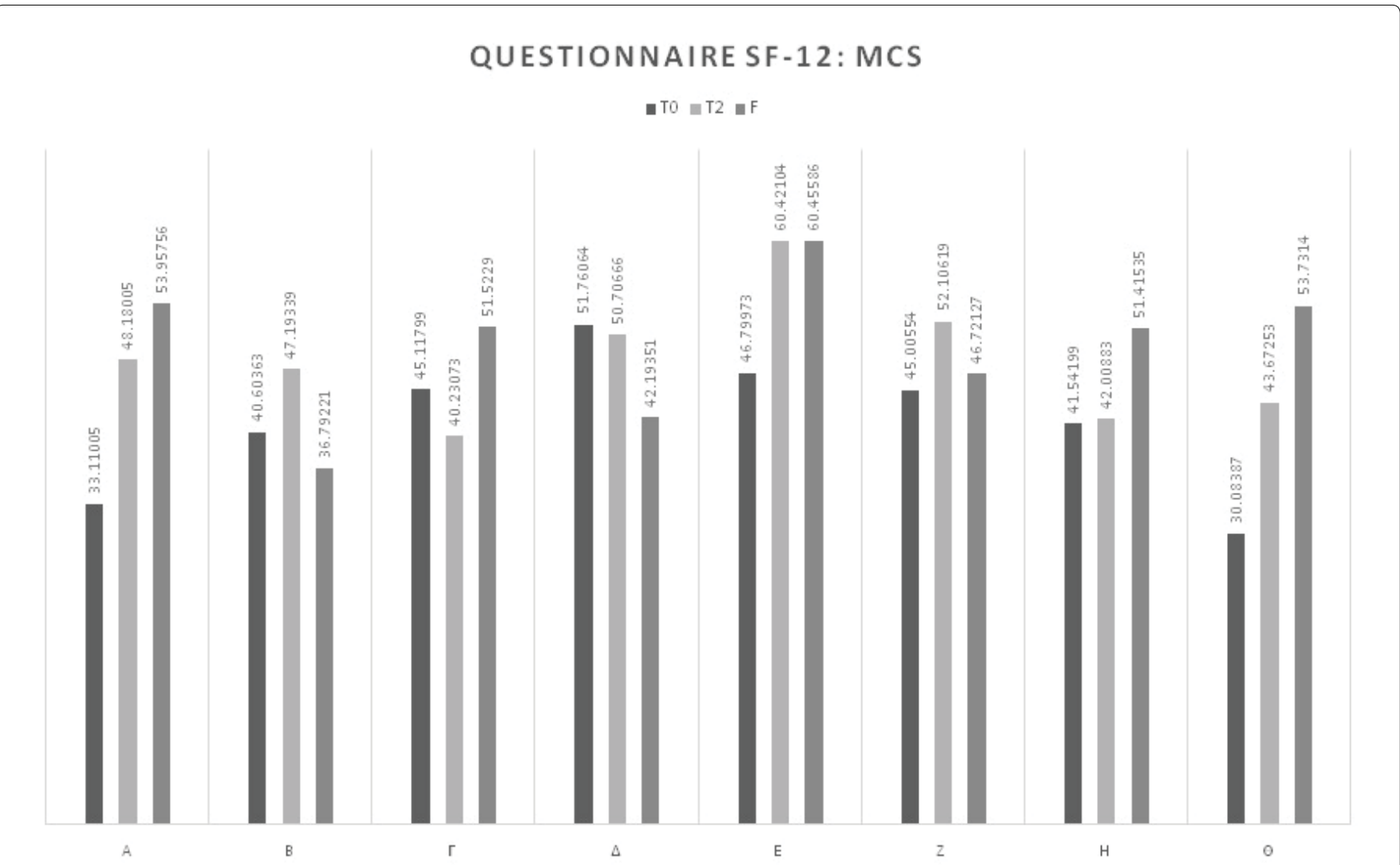

Figure 4: The diagram shows the variation of MCS-12 score during the treatment and in follow-up. MCS-12 investigates the mental aspects of quality of life.

Using an algorithm, an EQ-5D value was then calculated for each SF12 assessment of the subjects involved. At the start of therapy (T0) the average EQ-5D value was
0.76 . At the end of the treatment cycle (T2), an average score of 0.79 demonstrated that overall there was a not statistically significant improvement in perceived QoL. 


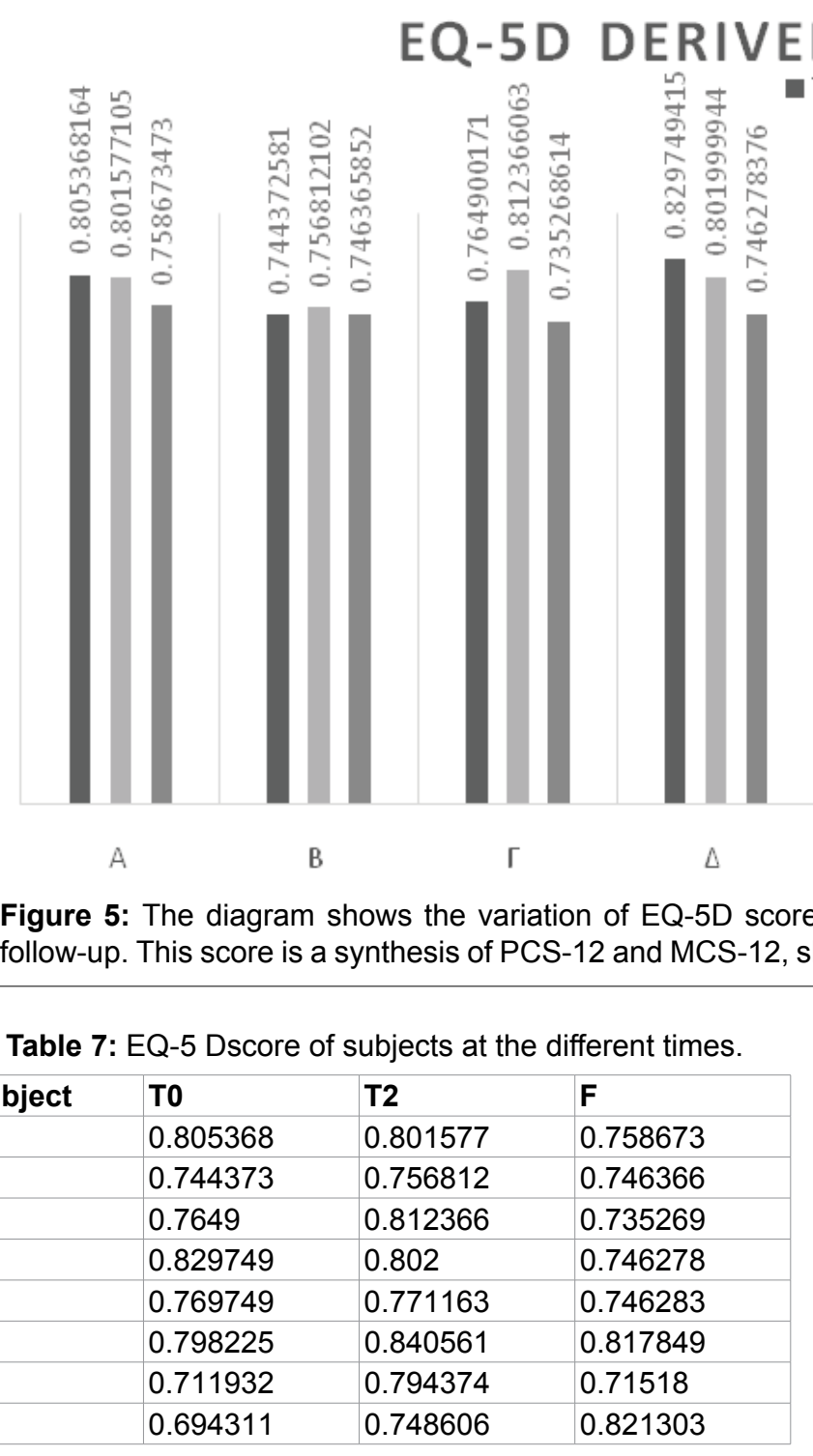

At the follow-up (F) the improved perceived QoL had declined to a value comparable to the T0 value (average $0.76)$.

\section{Joint Mobility}

The following table sets out the assessment of joint mobility (ART_M) of the subjects treated from T0 to F.

As already described above, since the joints and anatomical areas affected by OA were different in the various subjects, it was not possible to apply a single form of quantitative measurement but only qualitative using a dichotomy variable: a value of 1 was assigned for movement relative to the previous assessment and a value of 0 if there was no improvement, as seen in the table.

Compared to the NRS assessment of mobilization, assessment of joint mobility was divided into two distinct stages:

- Assessment of quality of movement under passive
Table 8: Improvement in joint mobility.

\begin{tabular}{|l|l|l|l|l|}
\hline Subject & T0 & T1 & T2 & F \\
\hline A & 0 & 1 & 1 & 1 \\
\hline B & 0 & 1 & 1 & 1 \\
\hline I & 0 & 1 & 1 & 1 \\
\hline$\Delta$ & 0 & 0 & 0 & 0 \\
\hline E & 0 & 1 & 1 & 0 \\
\hline Z & 0 & 0 & 0 & 0 \\
\hline H & 0 & 1 & 1 & 1 \\
\hline$\Theta$ & 0 & 1 & 1 & 1 \\
\hline
\end{tabular}

mobilization;

- Assessment of quality of movement under active mobilization.

The assessment of joint mobility was thus positive (dichotomy variable value 1) only when both the two stages had a positive outcome. If only one of the two stages showed an unchanged or negative outcome for improvement, the dichotomy variable was set to 0 (Table 8).

Therefore, starting from a score of 0 for every subject at $\mathrm{T} 0$, the improvement in both passive and active perceived joint mobility was $75 \%$ half way through the therapy (T1), with a further improvement of the same entity at the end of the cycle (T2).

At follow-up (F) this improvement in joint movement had declined to an improvement relative to T0 of $62.5 \%$.

Another interesting observation is that the only two 


\section{Analgesic Therapy On Demand Per Week}

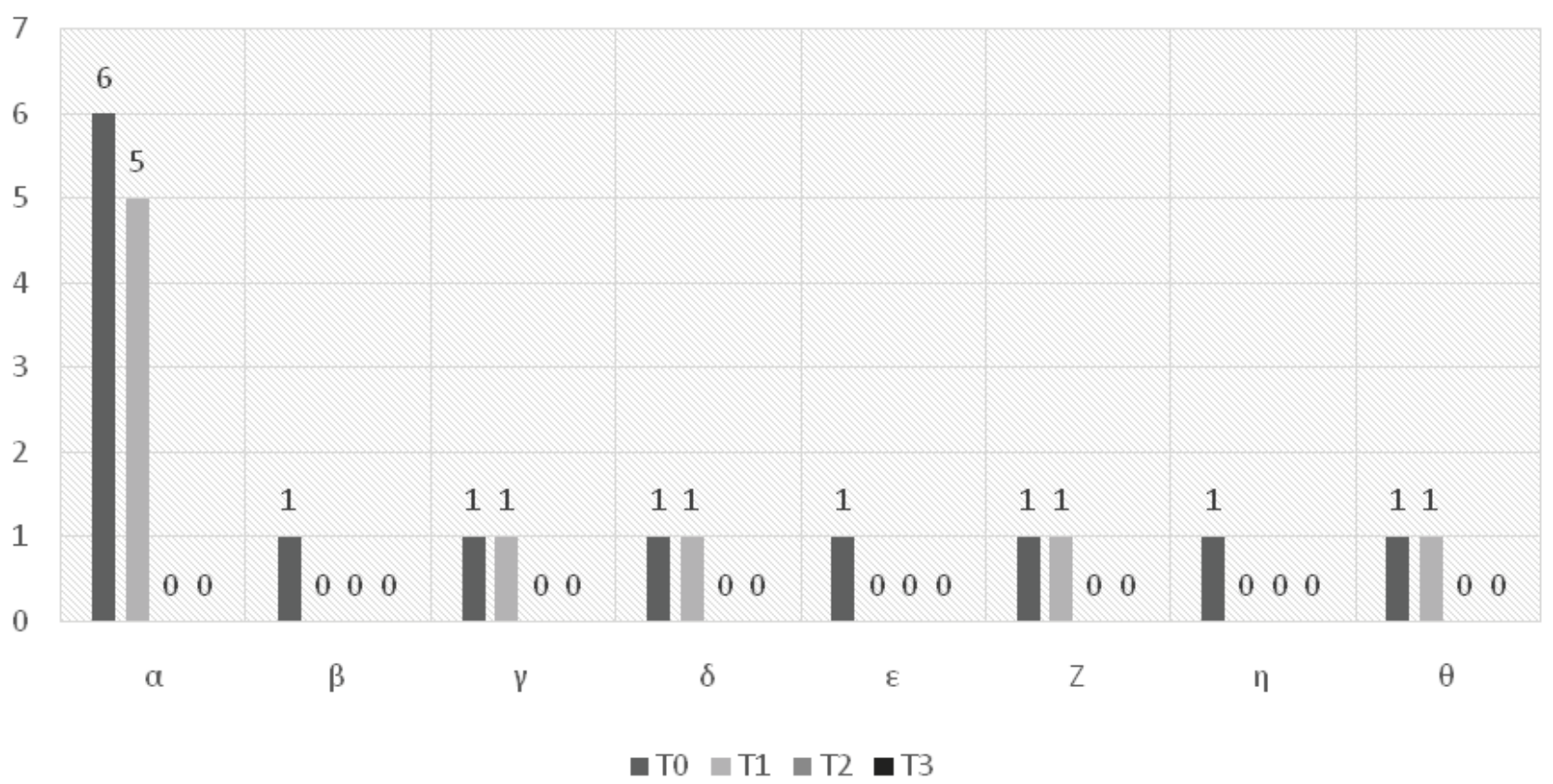

Figure 6: The diagram shows the reduction of analgesic drugs assumption on demand during the treatment and in follow-up.

Table 9: Use of Analgesic drugs on demand.

\begin{tabular}{|l|l|l|l|l|}
\hline Subject & T0 & T1 & T2 & F \\
\hline A & 6 & 5 & 0 & 0 \\
\hline B & 1 & 0 & 0 & 0 \\
\hline I & 1 & 1 & 0 & 0 \\
\hline$\Delta$ & 1 & 1 & 0 & 0 \\
\hline E & 1 & 0 & 0 & 0 \\
\hline Z & 1 & 1 & 0 & 0 \\
\hline H & 1 & 0 & 0 & 0 \\
\hline$\Theta$ & 1 & 1 & 0 & 0 \\
\hline
\end{tabular}

subjects who exhibited no improvement during both joint mobility assessment stages half way through the cycle were the same who continued to exhibit no improvements in subsequent measurements. In contrast $100 \%$ of the subjects who experienced an improvement in joint mobility in the two stages of assessment at $\mathrm{T} 1$ continued this trend in the second part of the treatment cycle (T2). This improvement was maintained in $83.33 \%$ of cases also after interruption of therapy.

\section{Use of Analgesic Drugs on Demand}

The following table sets out the use of analgesic drugs on demand (DOD) to control OA pain from T0 to F.

The sample weeks used for this assessment were those of the assessment of the other parameters: the first week of therapy (T0), the middle week of the treatment cycle (T1), the last week of treatment (T2), and the last week of the follow-up period $(\mathrm{F})$.

The administrations were noted $(1 \mathrm{drug}=1 \mathrm{admin}$ - istration) for analgesic drugs to the subjects involved in the study on their request to control pain, deriving both from $\mathrm{OA}$ and of other origins, in the week of analysis (Table 9 and Figure 6).

At the start of therapy (T0), the control of pain for the chronic therapies underway was already satisfactory, with an average administration of therapy on demand (therefore in addition to the chronic therapy) of 1.63 drugs per week. The need to consume analgesic drugs on demand for the control of pain diminished on average to 1.13 half way through the treatment cycle (T1) $\left(\mathrm{p}_{\text {To-T1 }}\right.$ $=0.033)$, diminishing to 0 at the end of treatment (T2) $\left(\mathrm{p}_{\mathrm{T} 0 \mathrm{-T} 2}=0.035\right)$.

Pain control was therefore stable between T2 and F, with an average request for analgesic drugs on demand of 0 per week $\left(\mathrm{p}_{\text {T0-F}}=0.035\right)$.

\section{Discussion}

Within residential facilities like the PAPS "Santa Maria", the role of the physiotherapist for treating $\mathrm{OA}$ is without doubt crucial, conducting all the conservative maneuvers on joints and administering physical therapies.

At the PAPS "Santa Maria" the use of ELF-EMF and in particular of ICR-like was completely unknown: this preliminary study thus permitted the physiotherapists to learn new skills and conservative approaches to the benefit of the residents. 
The clinical complexity of the RCH residents, combined with a high incidence of cognitive degeneration (more than $80 \%$ of the residents), did not permit a preliminary study with a large sample group. In fact, one of the major requirements at the start of the study was to understand how the use of ICR-like could be integrated into with the physiotherapeutic practices already underway. This made it necessary to simplify the task of the personnel by choosing a highly collaborative and reliable sample group. Furthermore, not all the available residents (among 20 residents) had an OA disturb diagnosed by a specialist or gave willingness to participate in this study.

This induced the adoption of a pilot study with one small population to assess impact on pain, QoL, joint mobility, and the use of analgesic drugs. Furthermore, the low number of participants, forbid us to perform a case-control study, limiting ourselves to carrying out a simple observational study.

The study had an overall duration of 12 months: it was initiated in the summer of 2016 and the final period of follow-up terminated at the end of the summer of 2017.

One problem encountered at the start was explaining in the simplest and clearest possible terms the type of treatment to elderly people of limited education and poorly disposed towards new technologies.

Nevertheless, except for a single case of abandonment after the first session due to the patient not having understood the type of treatment, there were no other cases of failed compliance with the ICR-like therapy.

In recent years there has been increasing attention to pain management. In Italy numerous hospital facilities have "hospital without pain" committees, these being bodies dedicated to promoting pain therapy and monitor good practice in this area. In this respect finding effective alternative instruments to drugs during the initial stages of pain, and complementary to drugs in the more advanced stages, is currently a very pressing objective, above all in contexts like care homes for the elderly where the attention to pain and QoL is central to everyday care.

Given these premises and the high incidence of $\mathrm{OA}$ among the subjects resident at the $\mathrm{RCH}$, it was decided to adopt a safe, conservative, non-invasive approach to the control of pain and disability caused by OA. Among the various physical therapies that of ELF-EMF is certainly the most adaptable and has the widest spectrum of potential action. Furthermore, the facility and ease of practical use, and the advantage of not being operator dependent (unlike other physical therapies) make it ideal in the context of physiotherapeutic activities at an $\mathrm{RCH}$, where much of the time of physiotherapists is necessarily dedicated to rehabilitation projects.

During the period of ICR-like treatments, no other kind of physiotherapeutic approaches for the enrolled patients were performed. Similarly, the chronic pharmacological treatments present at the time of enrollment remained unchanged, monitoring all the drug therapies change. In particular all the participants had as analgesic on demand acetamoniphen $500 \mathrm{mg} 1 \mathrm{cp}$ (repeatable up to $3 \mathrm{~g} /$ day, if necessary) and only 3 patients had a chronic pain therapy started before this study:

- $\alpha$ : Pregabalin $50 \mathrm{mg} \times 2 \mathrm{cp} /$ day since dec. 2015

- $\varepsilon$ : Tapentadol $50 \mathrm{mg} \times 2 \mathrm{cp} /$ day since dec. 2015

- $\theta$ : Acetaminophen $500 \mathrm{mg} \times 1 \mathrm{cp} /$ day since feb. 2016

These choices were necessary in order to have more confidence that the observed results were due to the ICRlike approach.

Pain reduction (NRS_R and NRS_M) was already noted by the subjects involved and the health personnel after the first month of treatment, with very significant results already at T1 both for NRS_R $\left(\mathrm{p}_{\mathrm{T}-\mathrm{T} 1}=0.033\right)$ and for NRS_M $\left(\mathrm{p}_{\text {T0-T1 }}=0.027\right)$. At T2 the pain check compared to the initial value was very satisfactory both for NRS_R $\left(\mathrm{p}_{\text {T0-T2 }}=0.024\right)$ and for NRS_M $\left(\mathrm{p}_{\text {T0-T2 }}=0.048\right)$, thus confirming the effectiveness of therapy with ICRlike for controlling pain in patients with OA. A slight negative shift in perceived pain was observed at T2 relative to $\mathrm{T} 1$. However, this was not significant, especially considering the pain results recorded at $\mathrm{F}$, when both values exhibited a reduction in perceived pain relative to $\mathrm{T} 2$, with a statistical significance relative to $\mathrm{T} 0$ both for NRS_R $\left(\mathrm{p}_{\mathrm{T} 0-\mathrm{F}}=0.015\right)$ and for NRS_M $\left(\mathrm{p}_{\mathrm{T} 0-\mathrm{F}}=0.011\right)$.

Considering the zero assumption of analgesic therapy on demand at $\mathrm{F}$, without any chronic analgesic therapy having been introduced or increased (if already present at $\mathrm{T} 0$ ), the result obtained at $\mathrm{F}$ can be assumed attributable to unknown and "delayed" effects of ELF-EMF therapy. The anti-inflammatory $[52,53,83,84]$ and in particular antioxidant effects [52,70,74-78] of ELF-EMF therapy have been known for some time, and it has been demonstrated both that improved local vascularization reduces pain in OA [5,85] and that ELF-EMF [86-88] also stimulates microcirculation. It is thus reasonable to assume that the biological mechanisms involved in these processes established an enhanced functional equilibrium thanks to the ICR-like therapy, continuing to improve even after interruption of therapy. This hypothesis needs support from further analogous observations involving larger numbers, but is certainly deserving of study for its possible health implications.

As regards pain, the impact of the therapy on the QoL 
was without doubt positive. The choice of the SF-12 [80] questionnaire was guided by extensive examples of use in Italy as well as by its ease of presentation to the subjects involved in the study, who might have encountered difficulty with the much more complete SF-36. The option of dividing the results into two main areas (physical and psychological) made it possible to analyze in more detail how the ICR-like therapy impacted the QoL of the subjects in this pilot study.

As regards the data collected with the PCS-12, the desired results were not achieved. During the months of treatment and then of follow-up the physical capability perceived by the subjects involved did not improve, instead exhibiting a deterioration, although not statistically significant. It is right to take into consideration that some of the people involved in the study had major disabilities which, outside of their OA, already impeded satisfactory mobility (4 of the 8 participants were already wheelchair-bound at the time of recruitment). Furthermore, the PCS-12 also takes into consideration the capacity for self care, which is not an issue strictly linked to OA.

Opposite results were achieved with the MCS-12, when the perceived improvement from a psychological perspective was significantly positive at the end of the treatment cycle $\left(\mathrm{p}_{\text {T0-T2 }}=0.049\right)$, with a further positive development at $\mathrm{F}\left(\mathrm{p}_{\mathrm{T} 0-\mathrm{F}}=0.049\right)$. In this respect the authors sustain that the impact achieved can be more incisively observed in the results of the NRS_R and NRS_M. A reduction in pain induced an improvement in mood and so improved the psychological ease of the subjects involved. The authors believe that it is important to give most weight to this aspect: pain causes not only physical disability but also emotional and psychological malaise. A reduction in pain is not always matched with improved general motor capacity, but the authors believe it is fair to affirm that reducing pain always leads to an improved emotional/psychological state, with definite positive repercussions on the social life of patients.

Upon completion of the study it was decided also to calculate an overall figure not divided between mind and body. An algorithm was used to calculate an EQ-5D value $[81,82,89]$ for each subject involved in the various measurements. This made it possible to establish how the QoL in general was improved at $\mathrm{T} 2$, without significance value $\left(\mathrm{p}_{\mathrm{T} 0-\mathrm{T} 2}=0.08\right)$; we observed also a regression in $\mathrm{QoL}$ at $\mathrm{F}$.

For the authors this last result confirms the dichotomy between PCS-12 and MCS-12; although the general impression and the recorded tendency suggest an improvement in the QoL linked to the ICR-like therapy, this statement needs more investigations to be confirmed.

The effect on joint mobility (ART_M) was more complicated to analyze since the subjects involved were treated for OA in different anatomical areas. As a consequence it was not possible to choose a univocal test in order to conduct a purely quantitative assessment. It was therefore decided to opt for an assessment based on a dichotomy variable, as explained in detail in the dedicated section above. The statistical significance cut off was taken as an overall improvement in the sample of at least $75 \%$.

This value was reached both at $\mathrm{T} 1$ and at $\mathrm{T} 2$, with a downturn to $62.5 \%$ at $\mathrm{F}$, but this figure rises to $83.3 \%$ if the two subjects definable as "non responders" per ART_M are excluded.

The figure can certainly be considered positive: ELFEMF therapy, principally through pain reduction, induced an improvement in the mobility of joints affected by OA, further reinforcing the positive impact on the social life of the subjects involved, as expressed in the improvement in MCS- 12 .

A further speculation regarding ART_M is possible. The data show that the two subjects that did not exhibit improvement at $\mathrm{T} 1$, continued to experience no improved mobility in subsequent measurements and both these subjects were suffering from cervical spondyloarthritis. It is possible that spondyloarthropathy, while responding from the perspective of pain control, does not benefit in mobility for heterogeneous factors (possible presence of unknown osteophytic beaks, or discopathy). However, the sample size was so tiny as to exclude anything other than speculative observations in this respect.

The use of analgesic drugs and in particular NSAIDs is one of the most widely used pain control strategies among subjects with OA $[1,8,9]$. However, the effects of this approach are only temporary and not without negative side effects [9].

Even though at T0 the sample under examination did not make extensive use of analgesic drugs, the assumption of a single additional drug by patients under poly pharmacy can lead to pharmacological interactions that are often poorly understood. Consequently, the results obtained already at $\mathrm{T} 1\left(\mathrm{p}_{\mathrm{TO}-\mathrm{T} 1}=0.033\right)$ and further improved at $\mathrm{T} 2$, relative to both the intermediate figure and the initial value $\left(\mathrm{p}_{\text {Tо-Т2 }}=0.035\right)$, can be considered very positive, also as regards limiting pharmaceutical costs per patient in addition to the objective reduction in perceived pain. In this respect the confirmation of reduced assumption of analgesic drugs at the follow-up $\left(\mathrm{p}_{\mathrm{T} 0 \mathrm{~F}}=\right.$ 0.035 ) was extremely satisfying.

It is noted also that none of the subjects involved experienced any side effects following the ELF-EMF therapy.

Finally, although the group was heterogeneous for the 
Citation: Greco A, Lorengo V, Malfatti N, et al. (2018) ICR-Like and Osteoarthritis in Geriatric Patients: Pilot Study at an RCH Facility. J Orthop Rheumatism 2(1):33-46

localization of OA (for the same reasons above), the authors believe that the obtained results demonstrate an interesting clinical value: the effects of ICR-like treatments observed seems to be nonspecific, but general for OA. As mentioned before the biological effects of ELF-EMF in the same range of frequencies and intensities of the fields used in this study involve the reduction of oxidative stress $[52,70,74-78]$, inflammation $[52,53,84]$ and stimulation of microcirculation [86-88], which are all at the basis of pathogenesis of OA $[4,6,7,85,90]$. For this reason the effects of ICR-like are appreciable in OA of different joints.

\section{Conclusions}

ICR-like therapy was found to be safe, easy to administer, and very effective for the treatment of the symptoms of OA, improving the psychological aspects of QoL of the subjects treated.

An observed reduction in the assumption of secondary pharmaceuticals is without doubt another positive outcome achieved with this complementary therapy.

Although the present pilot study was only conducted on a very small number of subjects, the statistical significance of the results produced an important turning point in the treatment of OA at the PAPS Santa Maria di Cles, with the hope that thanks to the present study it will be possible to recruit many more subjects at surrounding $\mathrm{RCH}$ facilities for a larger and more highly structured study.

\section{Conflicts of Interest}

Dr. Alessandro Greco declares that he provides scientific consultation in the development of new medical research for the company that manufactures the electromagnetic device used.

The other authors declare that no conflicts of interest exist. All costs for the present study were covered by the PAPS (Public Agency for Personal Services) RCH Cles, Italy.

\section{References}

1. Centers for Disease Control and Prevention (2011) Arthritis: The nation's most common cause of disability. Chronic disease at a glance reports - arthritis.

2. GBD 2015 Disease and Injury Incidence and Prevalence Collaborators (2016) Global, regional, and national incidence, prevalence, and years lived with disability for 310 diseases and injuries, 1990-2015: A systematic analysis for the Global Burden of Disease Study 2015. Lancet 388: 1545-1602.

3. March L, Smith EU, Hoy DG, et al. (2014) Burden of disability due to musculoskeletal (MSK) disorders. Best Pract Res Clin Rheumatol 28: 353-366.

4. Nigel Arden, Francisco J Blanco, Olivier Bruyère, et al (2015) Atlas of Osteoarthritis. Springer.

5. Carlo Morlacchi, Antonio Mancini (1985) Clinica Ortopedica. Manuale-atlante.
6. Wang P, Guan PP, Guo C, et al. (2013) Fluid shear stress-induced osteoarthritis: Roles of cyclooxygenase-2 and its metabolic products in inducing the expression of proinflammatory cytokines and matrix metalloproteinases. FASEB J 27: 4664-4677.

7. Berenbaum F (2013) Osteoarthritis as an inflammatory disease (osteoarthritis is not osteoarthrosis!). Osteoarthritis Cartilage 21: 16-21.

8. McAlindon TE, Bannuru RR, Sullivan MC, et al. (2014) OARSI guidelines for the non-surgical management of knee osteoarthritis. Osteoarthritis Cartilage 22: 363-388.

9. Van Laar M, Pergolizzi JV Jr, Mellinghoff HU, et al. (2012) Pain treatment in arthritis-related pain: Beyond NSAIDs. Open Rheumatol J 6: 320-330.

10. Arroll B, Felicity Goodyear-Smith (2004) Corticosteroid injections for osteoarthritis of the knee: Meta-analysis. BMJ 328: 869 .

11. Santaguida PL, Hawker GA, Hudak PL, et al. (2008) Patient characteristics affecting the prognosis of total hip and knee joint arthroplasty: A systematic review. Can J Surg 51: 428-436

12. Singh JA, Sperling J, Buchbinder R, et al. (2010) Surgery for shoulder osteoarthritis. Cochrane Database Syst Rev.

13. Hamilton De, Bywaters Eg, Please Nw (1959) Controlled trial of physiotherapy in arthritis. Br Med J 1: 542-544.

14. Kavuncu V, Evcik D (2004) Physiotherapy in rheumatoid arthritis. Med Gen Med 6: 3.

15. Hagen KB, Dagfinrud $H$, Moe RH, et al. (2012) Exercise therapy for bone and muscle health: An overview of systematic reviews. BMC Med 10: 167.

16. Michael T Cibulka, Douglas M White, Judith Woehrle PT, et al. (2009) Hip pain and mobility deficits-hip osteoarthritis: Clinical practice guidelines linked to the international classification of functioning, disability, and health from the orthopaedic section of the American Physical Therapy Association. J Orthop Sports Phys Ther 39: 1-25.

17. Derry S, Conaghan P, Da Silva JA, et al. (2016) Topical NSAIDs for chronic musculoskeletal pain in adults. Cochrane Database Syst Rev 4.

18. Chen YF, Jobanputra P, Barton P, et al. (2008) Cyclooxygenase-2 selective non-steroidal anti-inflammatory drugs (etodolac, meloxicam, celecoxib, rofecoxib, etoricoxib, valdecoxib and lumiracoxib) for osteoarthritis and rheumatoid arthritis: A systematic review and economic evaluation. Health Technol Assess 12: 1-278.

19. Hochberg MC, Altman RD, April KT, et al. (2012) American College of Rheumatology 2012 recommendations for the use of nonpharmacologic and pharmacologic therapies in osteoarthritis of the hand, hip, and knee. Arthritis Care Res (Hoboken) 64: 465-474.

20. Flood $\mathrm{J}$ (2010) The role of acetaminophen in the treatment of osteoarthritis. Am J Manag Care S48-S54.

21. Altman RD, Schemitsch E, Bedi A (2015) Assessment of clinical practice guideline methodology for the treatment of knee osteoarthritis with intra-articular hyaluronic acid. Semin Arthritis Rheum 45: 132-139.

22. Jüni $P$, Hari R, Rutjes AW, et al. (2015) Intra-articular corticosteroid for knee osteoarthritis. Cochrane Database Syst Rev. 
Citation: Greco A, Lorengo V, Malfatti N, et al. (2018) ICR-Like and Osteoarthritis in Geriatric Patients: Pilot Study at an RCH Facility. J Orthop Rheumatism 2(1):33-46

23. De Silva V, El-Metwally A, Ernst E, et al. (2011) Evidence for the efficacy of complementary and alternative medicines in the management of osteoarthritis: A systematic review. Rheumatology (Oxford) 50: 911-920.

24. Rosenbaum CC, O'Mathúna DP, Chavez M, et al. (2010) Antioxidants and antiinflammatory dietary supplements for osteoarthritis and rheumatoid arthritis. Altern Ther Health Med 16: 32-40.

25. Ashok Kumar Grover, Sue E Samson (2016) Benefits of antioxidant supplements for knee osteoarthritis: Rationale and reality. Nutr J 15: 1

26. Brosseau L, Welch V, Wells G, et al. (2004) Low level laser therapy (Classes I, II and III) for treating osteoarthritis. Cochrane Database Syst Rev.

27. Rutjes AWS, Nüesch E, Sterchi R, et al. (2010) Therapeutic ultrasound for osteoarthritis of the knee or hip. Cochrane Database Syst Rev.

28. Li S, Yu B, Zhou D, et al. (2013) Electromagnetic fields for treating osteoarthritis. Cochrane Database Syst Rev.

29. Ciafaloni $A$ (2007) Cyclotronic ion resonance therapy and arthralgia. Electromagn Biol Med 26: 299-303.

30. Jing D, Li F, Jiang M, et al. (2013) Pulsed electromagnetic fields improve bone microstructure and strength in ovariectomized rats through a Wnt/Lrp5/ 3 -catenin signaling-associated mechanism. PLoS One 8: e79377.

31. De Girolamo L, Stanco D, Galliera E, et al. (2013) Low frequency pulsed electromagnetic field affects proliferation, tissue-specific gene expression, and cytokines release of human tendon cells. Cell Biochem Biophys 66: 697-708.

32. Pavlović AS, Djurasić LM (2012) The effect of low frequency pulsing electromagnetic field in treatment of patients with knee joint osteoarthritis. Acta Chir lugosl 59: 81-83.

33. Ganesan K, Gengadharan AC, Balachandran C, et al. (2009) Low frequency pulsed electromagnetic field--a viable alternative therapy for arthritis. Indian J Exp Biol 47: 939-948.

34. Varani K, De Mattei M, Vincenzi F, et al. (2008) Characterization of adenosine receptors in bovine chondrocytes and fibroblast-like synoviocytes exposed to low frequency low energy pulsed electromagnetic fields. Osteoarthritis Cartilage 16: 292-304.

35. Naomi M Shupak, Julia C McKay, Warren R Nielson, et al. (2006) Exposure to a specific pulsed low-frequency magnetic field: A double-blind placebo-controlled study of effects on pain ratings in rheumatoid arthritis and fibromyalgia patients. Pain Res Manag 11: 85-90.

36. Kumar VS, Kumar DA, Kalaivani K, et al. (2005) Optimization of pulsed electromagnetic field therapy for management of arthritis in rats. Bioelectromagnetics 26: 431-439.

37. Trock DH, Bollet AJ, Markoll R (1994) The effect of pulsed electromagnetic fields in the treatment of osteoarthritis of the knee and cervical spine. Report of randomized, double blind, placebo controlled trials. J Rheumatol 21: 1903-1911.

38. Sutbeyaz ST, Sezer N, Koseoglu BF (2006) The effect of pulsed electromagnetic fields in the treatment of cervical osteoarthritis: A randomized, double-blind, sham-controlled trial. Rheumatol Int 26: 320-324.

39. Ryang We S, Koog YH, Jeong KI, et al. (2013) Effects of pulsed electromagnetic field on knee osteoarthritis: A systematic review. Rheumatology (Oxford) 52: 815-824.
40. Riva Sanseverino E, Vannini A, Castellacci P (1992) Therapeutic effects of pulsed magnetic fields on joint diseases. Panminerva Med 34: 187-196.

41. Jacobson JI, Gorman R, Yamanashi WS, et al. (2001) Low-amplitude, extremely low frequency magnetic fields for the treatment of osteoarthritic knees: A double-blind clinical study. Altern Ther Health Med 7: 54-64.

42. Harden RN, Remble TA, Houle TT, et al. (2007) Prospective, randomized, single-blind, sham treatment-controlled study of the safety and efficacy of an electromagnetic field device for the treatment of chronic low back pain: A pilot study. Pain Pract 7: 248-255.

43. Liboff AR (1997) Electric-field ion cyclotron resonance. Bioelectromagnetics 18: 85-87.

44. Liboff AR (2010) A role for the geomagnetic field in cell regulation. Electromagn Biol Med 29: 105-112.

45. Liboff AR (2013) Ion Cyclotron Resonance interactions in living systems. Atti IV Convegno Nazionale SIBE Pavia 1-14.

46. Liboff AR (2009) Electric polarization and the viability of living systems: Ion cyclotron resonance-like interactions. Electromagn Biol Med 28: 124-134.

47. Liboff AR (2007) Local and holistic electromagnetic therapies. Electromagn Biol Med 26: 315-325.

48. Vincze G1, Szasz A, Liboff AR (2008) New theoretical treatment of ion resonance phenomena. Bioelectromagnetics 29: 380-386.

49. Adey WR (1993) Whispering between cells: Elettromagnetic fields and regulatory mechanism in tissue: Frontier Perspect 21-25.

50. Alexander Lerchl, Russel J Reiter, Kimberly A Howes, et al. (1991) Evidence that extremely low frequency $\mathrm{Ca}^{2+}$-cyclotron resonance depresses pineal melatonin synthesis in vitro. Neurosci Lett 124: 213-215.

51. Liboff AR (1985) Geomagnetic cyclotron resonance in living cells. Journal of Biological Physics 13: 99-102.

52. Patruno A, Amerio P, Pesce M, et al. (2010) Extremely low frequency electromagnetic fields modulate expression of inducible nitric oxide synthase, endothelial nitric oxide synthase and cyclooxygenase- 2 in the human keratinocyte cell line HaCat: Potential therapeutic effects in wound healing. Br J Dermatol 162: 258-266.

53. Selvam R, Ganesan K, Narayana Raju KV, et al. (2007) Low frequency and low intensity pulsed electromagnetic field exerts its antiinflammatory effect through restoration of plasma membrane calcium ATPase activity. Life Sci 80: 2403-2410.

54. Bao X, Shi Y, Huo X, et al. (2006) A possible involvement of beta-endorphin, substance $P$, and serotonin in rat analgesia induced by extremely low frequency magnetic field. Bioelectromagnetics 27: 467-472.

55. Pilla AA (2013) Nonthermal electromagnetic fields: From first messenger to therapeutic applications. Electromagn Biol Med 32: 123-136.

56. Weintraub MI, Cole SP (2004) Pulsed magnetic field therapy in refractory neuropathic pain secondary to peripheral neuropathy: Electrodiagnostic parameters--pilot study. Neurorehabil Neural Repair 18: 42-46.

57. Ghione S, Seppia CD, Mezzasalma L, et al. (2005) Effects of $50 \mathrm{~Hz}$ electromagnetic fields on electroencephalographic alpha activity, dental pain threshold and cardiovascular parameters in humans. Neurosci Lett 382: 112-117. 
Citation: Greco A, Lorengo V, Malfatti N, et al. (2018) ICR-Like and Osteoarthritis in Geriatric Patients: Pilot Study at an RCH Facility. J Orthop Rheumatism 2(1):33-46

58. Rauš S, Selaković V, Radenović L, et al. (2012) Extremely low frequency magnetic field induced changes in motor behaviour of gerbils submitted to global cerebral ischemia. Behav Brain Res 228: 241-246.

59. Rauš S, Selaković V, Manojlović-Stojanoski M, et al. (2013) Response of hippocampal neurons and glial cells to alternating magnetic field in gerbils submitted to global cerebral ischemia. Neurotox Res 23: 79-91.

60. Chevalier X, Eymard F, Richette P (2013) Biologic agents in osteoarthritis: Hopes and disappointments. Nat Rev Rheumatol 9: 400-410.

61. Manikonda PK, Rajendra P, Devendranath D, et al. (2007) Influence of extremely low frequency magnetic fields on $\mathrm{Ca} 2+$ signaling and NMDA receptor functions in rat hippocampus. Neurosci Lett 413: 145-149.

62. Bennet Rodriguez M, Chauun Roche A (1997) Campo electromagnetico y respuesta immunoce llularen individuossanos. Rev Cubana Invest Biomed 16: 40-44.

63. Bettelli A, Montanari G, Lazzaroni T (1982) e coll. Effetti della elettromagnetoterapia sul dolore di varia etiologia. Atti XXXIV Congresso Nazionale S.I.A.A.R.T.I. Perugia.

64. Xu D, Zhang T, Qu J, et al. (2014) Enhanced patella-patellar tendon healing using combined magnetic fields in a rabbit model. Am J Sports Med 42: 2495-2501.

65. Hannemann PF, Mommers EH, Schots JP, et al. (2014) The effects of low-intensity pulsed ultrasound and pulsed electromagnetic fields bone growth stimulation in acute fractures: A systematic review and meta-analysis of randomized controlled trials. Arch Orthop Trauma Surg 134: 1093-1106.

66. Hu J, Zhang T, Xu D, et al. (2014) Combined magnetic fields accelerate bone-tendon junction injury healing through osteogenesis. Scand J Med Sci Sports 25: 398-405.

67. Yu JZ, Wu H, Yang Y, et al. (2014) Osteogenic differentiation of bone mesenchymal stem cells regulated by osteoblasts under EMF exposure in a co-culture system. J Huazhong Univ Sci Technolog Med Sci 34: 247-253.

68. Li JP, Chen S, Peng H, et al. (2014) Pulsed electromagnetic fields protect the balance between adipogenesis and osteogenesis on steroid-induced osteonecrosis of femoral head at the pre-collapse stage in rats. Bioelectromagnetics 35: $170-180$.

69. Morabito C, Rovetta F, Bizzarri M, et al. (2010) Modulation of redox status and calcium handling by extremely low frequency electromagnetic fields in $\mathrm{C} 2 \mathrm{C} 12$ muscle cells: A real-time, single-cell approach. Free Radic Biol Med 48: 579-589.

70. De Girolamo L, Viganò M, Galliera E, et al. (2014) In vitro functional response of human tendon cells to different dosages of low-frequency pulsed electromagnetic field. Knee Surg Sports Traumatol Arthrosc 23: 3443-3453.

71. Saggini R, Bellomo RG, Saggini A, et al. (2009) Rehabilitative treatment for low back pain with external pulsed electromagnetic fields. Int J Immunopathol Pharmacol 22: 25-28.

72. Ryaby JT (1998) Clinical effects of electromagnetic and electric fields on fracture healing. Clin Orthop Relat Res 355: 205-215.

73. Battisti E, Piazza E, Rigato M, et al. (2004) Efficacy and safety of a musically modulated electromagnetic field (TAMMEF) in patients affected by knee osteoarthritis. Clin Exp Rheumatol 22: 568-572.
74. Rossi E, Corsetti MT, Sukkar S, et al. (2007) Extremely low frequency electromagnetic fields prevent chemotherapy induced myelotoxicity. Electromagn Biol Med 26: 277-281.

75. Raggi F, Vallesi G, Rufini S, et al. (2008) ELF magnetic therapy and oxidative balance. Electromagn Biol Med 27: 325-339.

76. Vallesi G, Raggi F, Rufini S, et al. (2007) Effects of cyclotronic ion resonance on human metabolic processes: A clinical trial and one case report. Electromagn Biol Med 26: 283-288.

77. Ciejka E, Jakubowska E, Zelechowska P, et al. (2014) Effect of extremely low frequency magnetic field on glutathione in rat muscles. Med $\operatorname{Pr} 65:$ 343-349.

78. Rauš Balind S, Selaković V, Radenović L, et al. (2014) Extremely low frequency magnetic field $(50 \mathrm{~Hz}, 0.5 \mathrm{mT})$ reduces oxidative stress in the brain of gerbils submitted to global cerebral ischemia. PLoS One 9: e88921.

79. Ferreira-Valente MA, Pais-Ribeiro JL, Jensen MP (2011) Validity of four pain intensity rating scales. Pain 152: 2399-2404.

80. Haefeli M, Elfering A (2006) Pain assessment. Eur Spine J Suppl 1: S17-S24.

81. Lacson E Jr, Xu J, Lin SF, et al. (2010) A Comparison of SF-36 and SF-12 Composite Scores and Subsequent Hospitalization and Mortality Risks in Long-Term Dialysis Patients. Clin J Am Soc Nephrol 5: 252-260.

82. Johnson JA, Coons SJ (1998) Comparison of the EQ-5D and SF-12 in an adult US sample. Qual Life Res 7: 155-166.

83. Chuang LH, Kind P (2009) Converting the SF-12 into the EQ-5D: An empirical comparison of methodologies. Pharmacoeconomics 27: 491-505.

84. Johnson MT, Waite LR, Nindl G (2004) Noninvasive treatment of inflammation using electromagnetic fields: current and emerging therapeutic potential. Biomed Sci Instrum 40: 469-474.

85. Henrotin $Y$, Lambert C, Richette $P$, et al. (2014) Importance of synovitis in osteoarthritis: Evidence for the use of glycosaminoglycans against synovial inflammation. Semin Arthritis Rheum 43: $579-587$.

86. Delle Monache S, Angelucci A, Sanità P, et al. (2013) Inhibition of angiogenesis mediated by extremely low-frequency magnetic fields (ELF-MFs). PLoS One 8: e79309.

87. Bohn W, Hess L, Burger R (2013) The effects of the "physical BEMER ${ }^{\circledR}$ vascular therapy", a method for the physical stimulation of the vasomotion of precapillary microvessels in case of impaired microcirculation, on sleep, pain and quality of life of patients with different clinical pictures on the basis of three scientifically validated scales. J Complement Integr Med 10: S5-S12.

88. Klopp RC, Niemer W, Schulz J (2013) Complementary-therapeutic stimulation of deficient autorhythmic arteriolar vasomotion by means of a biorhythmically physical stimulus on the microcirculation and the immune system in 50-year-old rehabilitation patients. J Complement Integr Med 10: S29-S37.

89. Patrick W Sullivan, Vahram Ghushchyanal (2006) Mapping the EQ-5D index from the SF-12: US general population preferences in a nationally representative sample. Med Decis Making 26: 401-409.

90. Sieroń A, Labus $\measuredangle$, Nowak P, et al. (2004) Alternating extremely low frequency magnetic field increases turnover of dopamine and serotonin in rat frontal cortex. Bioelectromagnetics 25: 426-430. 